Ethiopian Journal of Environmental Studies \& Management 10(5): 675 - 690, 2017.

ISSN:1998-0507

doi: https://dx.doi.org/10.4314/ejesm.v10i5.11

Submitted: April 12, 2017

Accepted: July 12, 2017

\title{
ASSESSMENT OF LABILE METALS IN EFFLUENTS FROM LUBRICATING OIL COMPANY IN OSOGBO OSUN STATE, NIGERIA
}

\author{
ADENIJI, A.0., *OLABANJI, I.0. AND OLUYEMI, E.A.
}

Department Chemistry, Faculty of Science, Obafemi Awolowo, University, Ile-Ife, Nigeria

\begin{abstract}
Effluent and sediment samples were collected on seasonal basis, comprising of three months (August to October, 2014) in the wet season and three months (December 2014 to February 2015) in the dry season from five points around a lubricating oil company in Osogbo - Nigeria. The sequential extraction method was used to respectively fractionate the sediment and effluent samples, then analyzed by Atomic Absorption Spectrophotometry (AAS) to determine concentrations of five heavy metals: $\mathrm{Mn}, \mathrm{Ni} \mathrm{Co}, \mathrm{Cd}$ and $\mathrm{Pb}$. Results showed that in wet season, higher concentration of $\mathrm{Mn}$ was found in exchangeable fraction, $\mathrm{Ni}$ and $\mathrm{Pb}$ were more pronounced in carbonate bound fraction, $\mathrm{Cd}$ in Fe-Mn oxide fraction, while Co was more in residual fraction. In dry season, $\mathrm{Pb}$ was more concentrated in exchangeable fraction, $\mathrm{Co}$ in residual fraction, $\mathrm{Mn}$ in Fe-Mn oxide fraction, $\mathrm{Cd}$ in organic matter bound, while Ni was more concentrated in the carbonate fraction. In both seasons for sediment samples, $\mathrm{Cd}$ concentrations were found above the set limit by WHO. The speciation study of the effluent showed that, $\mathrm{Mn}, \mathrm{Co}$ and $\mathrm{Ni}$ concentration were found more in Organic substances fraction in both seasons, $\mathrm{Pb}$ was more concentrated in free metal ion fraction in wet season while it was high in organic fraction in the dry season. Concentrations of all metals in the effluent samples in both seasons were above the maximum permissible limit for effluent. The high mobility factors of heavy metals in the sediment indicated that the metals were labile and bioavailable thereby making the soil and the living organisms vulnerable to possibility of high heavy metal bioaccumulation.
\end{abstract}

Key Words: Heavy Metals, Speciation, Effluents, Sediment

\section{Introduction}

In the history of man, the use of metals has a great benefits and as well its unexpected consequences (Amore et al., 2005). Metals get into the environment from variety of sources, including those naturally occurring biogeochemical cycle (Juan et al., 2010; Tessier et al., 1979) and also from anthropogenic sources, namely from domestic, industrial effluents, urban, storm water, run-off and atmospheric sources (Forstner and Wittman, 1981).

Although determination of total metal concentrations have been applied widely but is not enough method to know the mobility and bioavailability of heavy metals in the effluent and sediment and 
their potential impact on the environment because it depend on the chemical form of heavy metals (Amos et al., 2014, Alvarez et al., 2002). Speciation of heavy metals in effluent and associated sediments gives better understanding of the extent of mobility and bioavailability of different metal fractions and its application for agricultural purposes.

Total metal evaluation alone cannot really show the metal that is bioavailable because it may be poor indicators of uptake by plants. Hence, to evaluate and quantify different chemical forms of metals in samples such as sediments and effluent, employing appropriate method during extraction procedure are more essential than before. Among numerous sequential extraction procedures (SEPs) that have been developed for sediment samples, the 5-step SEP by Tessier et al. (Tessier et al., 1979), short SEP by Maize (Maize et al., 1997), the 6-step KerstenFörstner procedure (Kersten and Förstner, 1986) are the three most standard methods for speciation of metals. Also for water speciation the 3step SEP by Tokalioglu et al. (2000) is the most standard method for speciation metals of an environmental material.

The speciation of heavy metals shows strong influences on the mobility, bioavailabilty and toxicity of heavy metals in both contaminated sediment and waste water (Ure and Davidson 2002; Hass and Fine 2010; Qingsong et al., 2013).

For sediment samples, Tessier et al., (1979) classifies forms of heavy metal into separate fractions:

Exchangeable: The exchangeable form of heavy metals is mobile and it is used to quantify the short term availability of heavy metals for plants uptake
(Brummer, 1986, Amos et al., 2014). It occurs in ion exchange complexes. Metal bound to carbonate can also be easily released at lowered soil reaction available to plant (Gawdzik and Gawdizik, 2012, Amos et al., 2014).

The important factor governing metal speciation is the hydrogen ion activity (pH). $\mathrm{pH}$ affect both solubility of metal hydroxide mineral and adsorptiondesorption process. Under high $\mathrm{pH}$ condition in water, metal hydroxide minerals have very low solubility because its activity is proportional to $\mathrm{pH}$ (Amos et al., 2014).

Metal adsorbed to oxides: Oxide of aluminium, manganese and iron provides sites for chemical adsorption of metals (Amos et al., 2014). Adsorption that occurs when metals are attached to surfaces of particulate matter is also strongly dependent on $\mathrm{pH}$ (Bourg, 1988; Brummer, 1986; Amos, 2014). Adsorption also vary with concentration of complexing agent also increase $\mathrm{pH}$ of the adsorption (Amos, 2014; Bourg, 1998) and precipitation of heavy metals with oxide, hydroxide, but carbonates decreasing the mobility of the metal (Jenne, 1986; Amoset al., 2014). Metal that bounded to oxide are very stable but dangerous because when it undergo reduction-oxidation condition in the soil they can be made available overtime time.

Metal bounded to organic matter: According to Brummer, metal bound to organic matter fraction are very stable in the soil and not available for plant (Brummer, 1986). Complexation of heavy metal with dissolved organic matter can cause it mobility which increases the extent of leaching of metal 
in the soil (Molenaar and Belttrami 1998; Schaecke et al., 2002; Amos et al., 2014).

Bio-availability of heavy metal can reduce because of the decrease in organic matter decomposition overtime (Mcbride, 1995; Schmidt 1997). According to Silveira et al., the more electronegative the metal ion, the strong it bounded with organic matter (Silveria et al., 2003)

Metal in the residual fraction: The residual fraction of heavy metals is considered the inactive fraction as regard chemical processes in the soil. They are found in between the mineral layer and on edge clay layer (Amos et al., 2014; Calvet et al., 1989)

\section{Materials and Methods}

Sample Collection and Pre-treatment
The effluent and sediment samples were collected in $1 \mathrm{~L}$ treated polyethylene bottles from five different sites along the discharge path of the lubricating oil company in Osogbo in wet (August, September, October) and dry season (December, January, Febuary) respectively.The geographical locations of these sites were determined using GPS-Magellian GPS 3010. The map of the study area (Fig. 1) depicts the sampling sites in Osogbo Osun State, Nigeria.

Tables 1 present the geographical locations of the sampling site. The study area lies within longitudes $4^{\circ} 31^{\prime} 0.41^{\prime \prime}$ to $4^{\circ} 31^{\prime} 07.1^{\prime \prime}$ and latitudes $7^{\circ} 47^{\prime} 13.1^{\prime \prime}$ to $7^{\circ} 47^{\prime} 13.7^{\prime \prime}$ while the land elevation is within $37.66 \mathrm{~m}$ to $78.12 \mathrm{~m}$ above sea level.

Table 1: Geographical Locations of the Sampling Sites in Osogbo

\begin{tabular}{|c|c|c|c|}
\hline Sampling site & Elevation (m) & $\begin{array}{l}\text { GPS Values } \\
\text { Latitude }(\mathrm{N})\end{array}$ & Longitude (E) \\
\hline Point 1 & 66.96 & 7047'13.7'” & $4^{\circ} 31^{\prime} 06.9^{\prime \prime}$ \\
\hline Point 2 & 50.22 & 7047'13.1"' & $4^{\circ} 31^{\prime} 07.1^{\prime \prime}$ \\
\hline Point 3 & 36.27 & 7047'13.1"' & $4^{\circ} 31^{\prime} 06.5^{\prime \prime}$ \\
\hline Point 4 & 78.12 & 7047'13.3”' & 4031'04.8”' \\
\hline Point 5 & 55.80 & 7047'13.5”' & $4^{\circ} 31^{\prime} 0.41^{\prime \prime}$ \\
\hline Control point & 37.66 & 7047'13.2”' & $4^{\circ} 31^{\prime} 02.7^{\prime \prime}$ \\
\hline
\end{tabular}


Assessment of Labile Metals in Effluents from Lubricating Oil................ADENIJI et al.

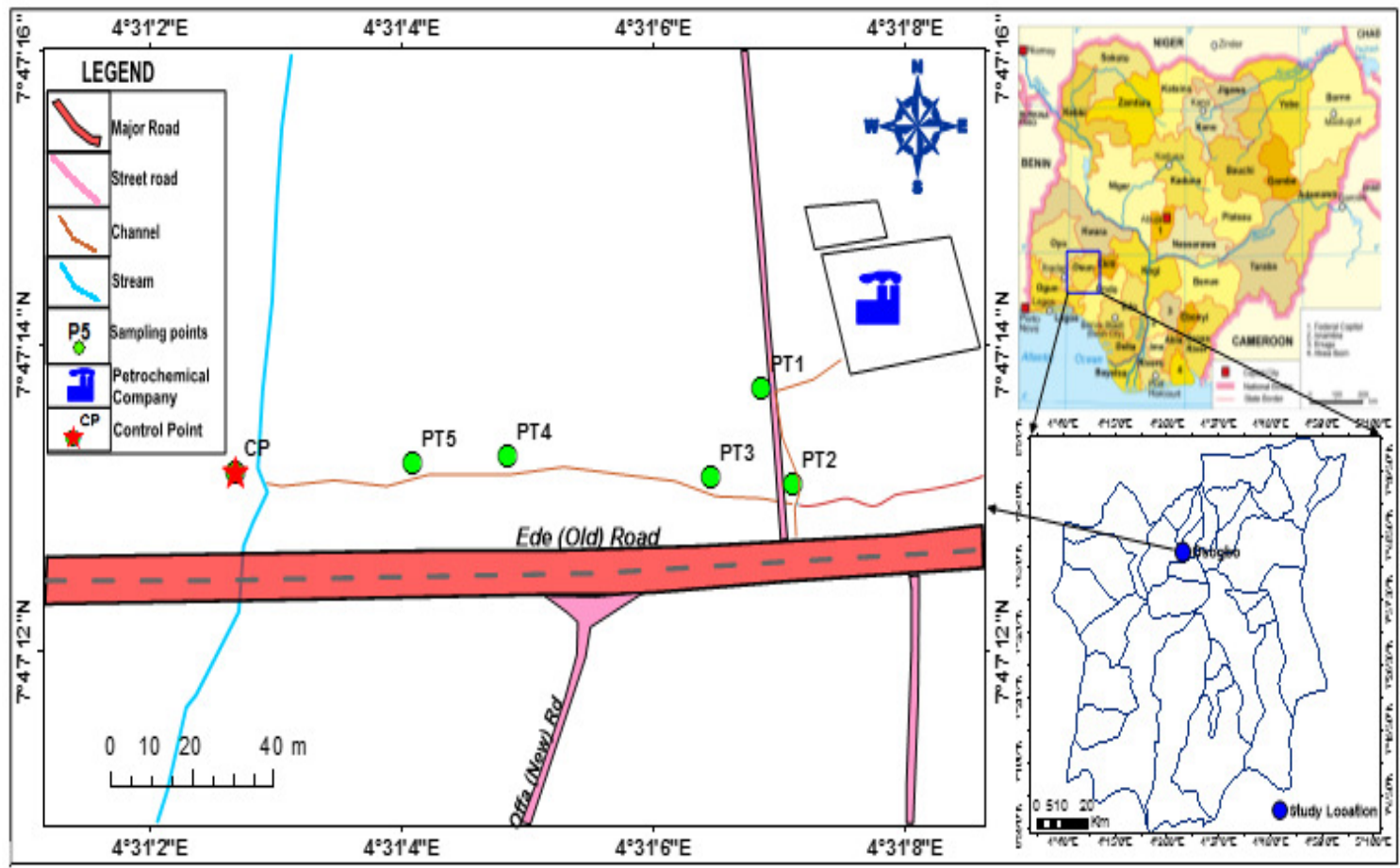

Fig. 1: The locations of the sampling sites in Osogbo

Determination of Total Metal Concentration in Sediment Samples

One gram of sediment sample was digested with $30 \mathrm{~mL}$ aqua regia $(\mathrm{HC} 1$ : $\left.\mathrm{HNO}_{3} ; 3: 1\right)$ on a hot plate equipped with a thermostated at a temperature between $150{ }^{\circ} \mathrm{C}$ and $180{ }^{\circ} \mathrm{C}$. The contents of the Teflon beaker were replenished with more aqua regia to avoid total evaporation. After approximately two hours of digestion, $5 \mathrm{~mL} \mathrm{HF}$ was added to the Teflon beaker and the temperature of the hot plate was decreased to induce simmering. The sample was then digested for a further 30 minutes. The Teflon beaker containing the sample was allowed to cool to room temperature before it was quantitatively transferred into a $25 \mathrm{~mL}$ volumetric flask and filled to capacity with twice distilled water. A blank determination was conducted using the procedure described above, without the sample. Concentrations of $\mathrm{Mn}, \mathrm{Ni}$,
$\mathrm{Co}, \mathrm{Cd}$ and $\mathrm{Pb}$ were determined by Atomic Absorption Spectrophotometry at the Centre for Energy Research and Development (CERD), Obafemi Awolowo University, Ile-Ife, Nigeria.

Sequential Extraction of Metals from Sediment Samples

A sequential extraction procedure (Tessier et al., 1979) was used to extract and partition $\mathrm{Mn}, \mathrm{Ni} \mathrm{Co}, \mathrm{Cd}$ and $\mathrm{Pb}$ into exchangeable, bound-to-carbonate, bound to Fe-Mn oxides, bound to organic matter and residual fraction species.

Exchangeable (F1): A 1.0 g sample was extracted from the sediment sample with $20 \mathrm{~mL} 1 \mathrm{M} \mathrm{MgCl} 2$ by continuous agitation for one hour at room temperature.

Carbonate-bound (F2): The residue from F1 was treated at room temperature with $20 \mathrm{~mL} 1 \mathrm{M} \mathrm{CH}_{3} \mathrm{COONa}$ adjusted to $\mathrm{pH}=5$ with $\mathrm{CH}_{3} \mathrm{COOH}$, and continuous agitation were maintained for five hours. 
Fe-Mn oxide bound (F3): The residue from $\mathrm{F} 2$ was extracted with $40 \mathrm{~mL} 0.04 \mathrm{M}$ $\mathrm{NH}_{2} \mathrm{OH} . \mathrm{HCl}$ in $25 \%$ (v/v) $\mathrm{CH}_{3} \mathrm{COOH}$ with occasional agitation for five hours.

Bound to organic matter (F4): The F3 residue was added to $7.5 \mathrm{~mL}$ of $0.02 \mathrm{M}$

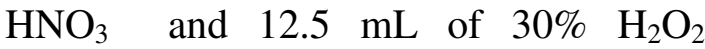
adjusted to $\mathrm{pH}=2$ with $\mathrm{HNO}_{3}$. The mixture was heated to $85{ }^{\circ} \mathrm{C}$ for two hours with occasional agitation. A second aliquot containing $7.5 \mathrm{~mL}$ of $30 \% \mathrm{H}_{2} \mathrm{O}_{2}$ was added and further heated for three hours at $85^{\circ} \mathrm{C}$ with intermittent agitation. After cooling, $12.5 \mathrm{~mL}$ of $3.2 \mathrm{M}$ $\mathrm{CH}_{3} \mathrm{COONH}_{4}$ in $20 \%$ (v/v) $\mathrm{HNO}_{3}$ was added to prevent the adsorption of the extracted metals into oxidized sediments. The mixture was then diluted to $40 \mathrm{~mL}$, followed by 30 minutes of continuous agitation.

Residual (F5): The residue from F4 was digested by $15 \mathrm{~mL}$ of concentrated $\mathrm{HNO}_{3}$ and then refluxed for one hour, filtered and washed with $10 \mathrm{~mL}$ of hot $3 \mathrm{M} \mathrm{HNO}_{3}$.

\section{Resin and Column Preparation}

The Amberlite XAD-16 resin was ground to enlarge the surface area for maximum adsorption and sieved with 60-80 mesh before being washed successively with methanol, water, $1 \mathrm{M} \mathrm{HNO}_{3}$ in acetone, water, $1 \mathrm{M} \mathrm{NaOH}$ and water. A sample of $400 \mathrm{mg}$ of Amberlite XAD-16 resin was slurry-packed into a glass column (10 $\mathrm{mm}$ i.d (internal diameter) x $100 \mathrm{~mm}$ length) fitted with glass wool. Prior to use, the column was preconditioned with $5-10 \mathrm{~mL}$ portions of blank solution (distilled water). Concentrations of $\mathrm{Mn}$, $\mathrm{Ni}, \mathrm{Co}, \mathrm{Cd}$ and $\mathrm{Pb}$ were determined by Atomic Absorption Spectrophotometry.

\section{Speciation Analysis for Effluent Samples}

Following the determination of heavy metals in effluent samples after sorption on Amberlite XAD-16 resin, the speciation of effluent samples was separated into three fractions (Tokalioglu et al., 2000): metals in suspended particles, metals bound to organic substances and free metal ions.

Metals in suspended particles: Effluent samples were filtered through a $0.45 \mu \mathrm{m}$ Millipore membrane filter $(47 \mathrm{~mm}$ in diameter). The membrane filters loaded with suspended particles were dissolved in concentrated $\mathrm{HNO}_{3}$, centrifuged, evaporated to near dryness and then collected in $2 \mathrm{~mL}$ samples with $2 \mathrm{M}$ $\mathrm{HNO}_{3}$.

Metals bound to humic substances: The effluent samples were filtered through a $0.45 \mu \mathrm{m}$ filter, and the obtained filtrates were passed through adsorbent column packed with Amberlite XAD-16 resin at a flow rate of $2-2.5 \mathrm{~mL} \mathrm{~min}^{-1}$. The effluent was reserved in order to determine the free metal ion contents. The metals bound to humic substances were then eluted with $1 \mathrm{M} \mathrm{HCl}$ in acetone. Free metal ions: A $2 \mathrm{~mL}$ sodium tetra borate reagent was added to the effluent. The solution was passed through the column filled with Amberlite XAD-16 resin. The trace metals adsorbed on the resin were eluted with $1 \mathrm{M} \mathrm{HCl}$ in acetone, and the residue was dissolved in $0.7 \mathrm{~mL}$ of $2 \mathrm{M} \mathrm{HNO}_{3}$.

Mobility Factor (MF) Determination

The relationship adopted by (Salbu et al., 1998; Narwal and Singh, 1998) was used to determine the mobility factor of the metals. This relationship is: 
Assessment of Labile Metals in Effluents from Lubricating Oil.................ADENIJI et al.

$$
M F=\frac{F_{1}+F_{2}}{F_{1}+F_{2}+F_{2}+F_{4}+F_{\mathrm{g}}} X 100
$$

Where: $\mathrm{F}_{1}=$ Exchangeable metal content fraction, $\mathrm{F}_{2}=$ Metal content bound to carbonate fraction, $\mathrm{F}_{3}=$ Metal content bound to Fe-Mn oxide fraction, $\mathrm{F}_{4}=$ Metal content bound to organic matter fraction, $\mathrm{F}_{5}=$ Residual metal content fraction.

\section{Risk Assessment Code (RAC)}

Risk assessment code (RAC) was first adopted by Singh et al., 1997. RAC is to assess the availability of metals in the sediment. This relationship is:

$$
\% \mathrm{~F} 1+\% \mathrm{~F} 2 \text {. }
$$

Where: F1 = Percentage exchangeable metal content fraction, F2 = Percentage metal bound to carbonate fraction.

The mobility and stability of elements which relatively define their toxicity strongly depend on binding forms in different phases. According to RAC classification, less than $1 \%$ of total metal in exchangeable/carbonate phase has no adverse impact on aquatic environment. Low risk defined in range between $1 \%$ and $10 \%$ while medium risk is $11-30 \%$ and $31-50 \%$ indicates high risk. Higher percentage than $50 \%$ of the total metal has very high risk and can poses dangerous impact by entering into food chain.

\section{Results and Discussion}

The results of the speciation analysis on sediments for some heavy metals are provided in Fig. 2 and Fig. 3 for wet and dry season respectively. As you move down along the path (point 1 to point 5) of discharge, accumulation of the metals $(\mathrm{Pb}, \mathrm{Ni}$ and $\mathrm{Co})$ in exchangeable and carbonate increases which makes the near- by river the sink of the effluent (Fig. 1) and its aquatic organism at risk. The results indicate an occurrence of the highest Mn percentage in exchangeable fraction in wet season and Fe-Mn oxide fraction in dry season. Adeyeye et al. (2016) also reported that a Mn quantity is high in the exchangeable fraction in the runoff sediment collected from osogbo. This is an indication that Mn availability in the sediment being investigated is likely to be lithogenic in origin in wet season. The least concentration of $\mathrm{Mn}$ appeared in the organic matter and residual fraction. The concentrations of Mn analyzed in both seasons were found below permissible limits of $1000 \mu \mathrm{g} / \mathrm{g}$ set by WHO (2003). For $\mathrm{Ni}$, the speciation result shows that it had highest accumulation in carbonate fraction in both wet and dry season which could make $\mathrm{Ni}$ to be available in the sediment at the slighted change in $\mathrm{pH}$ (Amos et al., 2014). The concentrations of $\mathrm{Ni}$ analyzed in both wet and dry season were below the recommended permissible limit of 50 $\mu \mathrm{g} / \mathrm{g}$ by WHO. Speciation pattern of $\mathrm{Cd}$ shows that in wet season, the lowest concentration of $\mathrm{Cd}$ in the fraction was obtained in the residual fraction but in dry season it was low in Fe-Mn oxide. However, the highest concentration was obtained in Fe-Mn oxide in wet season and high in the organic matter fraction in dry season. High concentration of $\mathrm{Cd}$ in non-residual fraction indicates that it may be easily transferred into the food chain with time (Pardo and Guadalix, 1996). 
The concentrations of $\mathrm{Cd}$ analyzed in both seasons were found above permissible limits of $(3 \mu \mathrm{g} / \mathrm{g})$ set by WHO for sediment. These metals will bioaccumulate and stored faster than excreted (Abdel-shafy and Abdel-basir, 1991; Antunes et al., 2003; Davies et al., 2006). Cadmium exposure during human pregnancy, leads to reduced birth weights and premature birth (Henson and Chedrese, 2004). Long-term exposure leads to a buildup in the kidneys and possible kidney disease, lung damage, and fragile bones (ATSDR, 2008). In the sediment, Co predominated in this order; residual fraction $>\mathrm{Fe}-\mathrm{Mn}$ oxide $>$ organic matter. Carbonate fraction in wet season shows high immobility of Co (Amos et al., 2014), but in dry season carbonate fraction had the highest concentration. However, the concentrations of Co analyzed in both wet and dry season were below the recommended permissible limit of $50(\mu \mathrm{g} / \mathrm{g})$ by WHO in sediment. The accumulation of $\mathrm{Pb}$ in both seasons was high in the carbonate fraction and this can be made available to the environment at the slightest change in $\mathrm{pH}$ of the sediment (Amos et al., 2014). The concentration of $\mathrm{Pb}$ analyzed in both seasons were below the set permissible limit of $100 \mu \mathrm{g} / \mathrm{g}$ by WHO (2003) in sediment. 


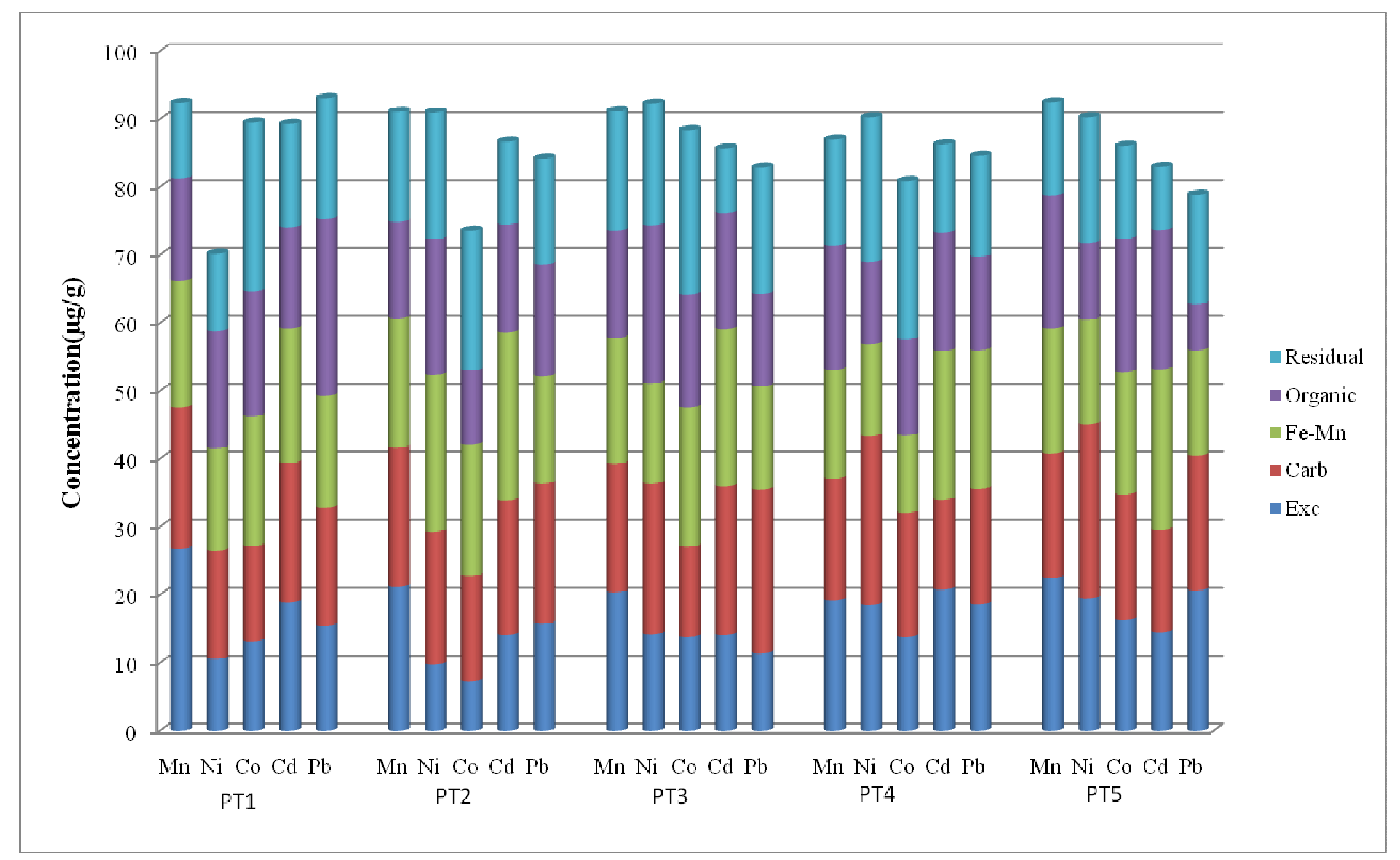

Fig. 2: Summary of total mean levels of heavy metals $(\mu \mathrm{g} / \mathrm{g})$ in each fractions sediment samples in wet season 


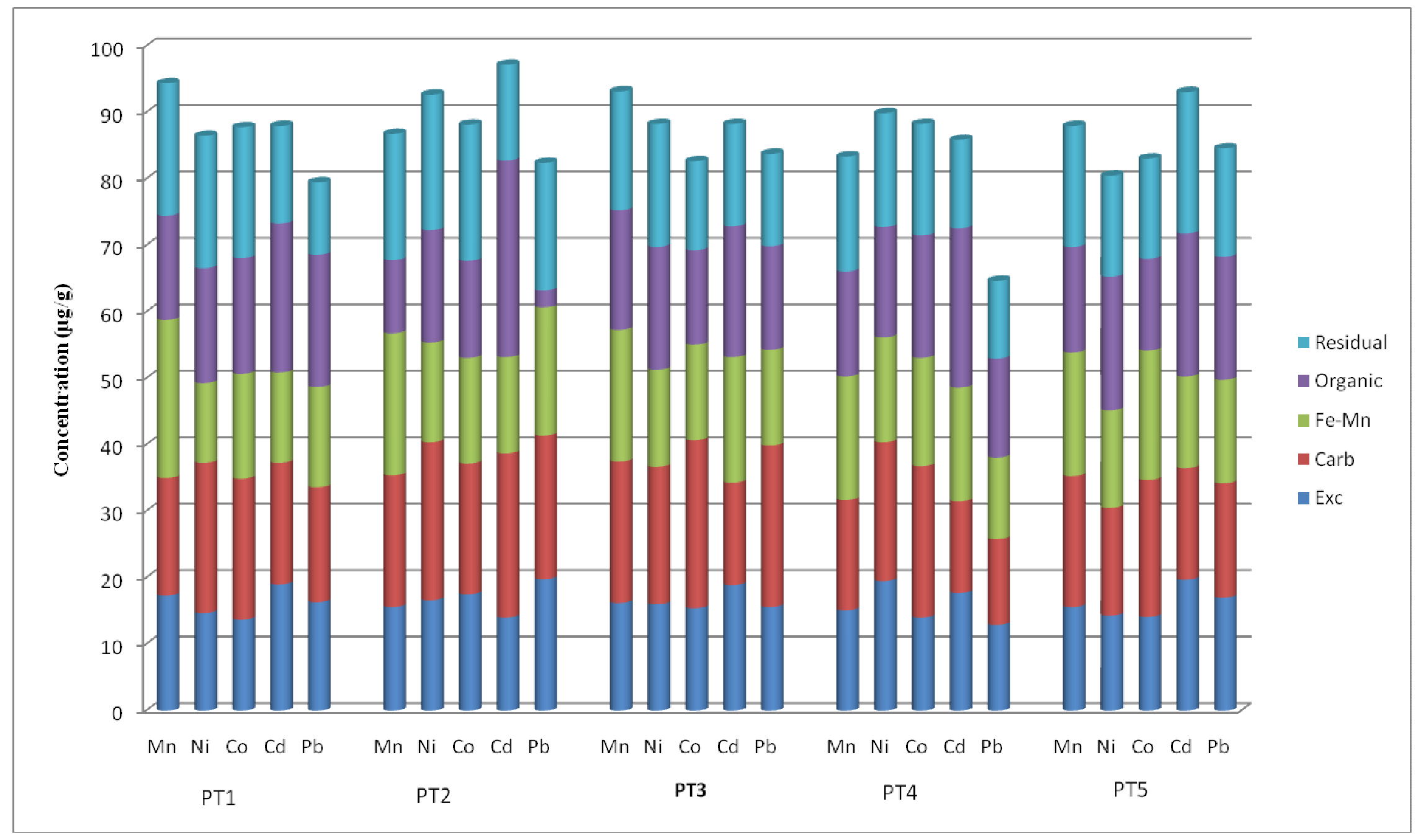

Fig. 3: Summary of total mean levels of heavy metals $(\mu \mathrm{g} / \mathrm{g})$ in each fractions sediment samples in dry season 
The overall mean of the mobility factor MF for the heavy metals studied (Table 2) were in the order: Co $(33.85 \%)$ $<\mathrm{Cd}(37.78 \%)<\mathrm{Ni}(40.99 \%)<\mathrm{Pb}$ $(43.70 \%)<\mathrm{Mn}(45.42 \%)$ for wet season and $\mathrm{Mn}(39.41 \%)<\mathrm{Cd}(39.62 \%)$ $<\mathrm{Ni}(41.52 \%)<\mathrm{Co}(42.24 \%)<\mathrm{Pb}$ $(43.92 \%)$ for dry season. In wet and dry seasons, the mobility factor showed that the levels of $\mathrm{Ni}$ and $\mathrm{Pb}$ were high confirming values obtained in their chemical speciation study. All these metals can be said to be highly environmentally labile and bioavailable (Xian, 1987; Salbu et al., 1998). However, all the humans, plants, animals around this area are quite vulnerable to the heavy metals exposure.

\section{Risk Assessment Code (RAC)}

The calculated values (Table 2) according to equation 2 by Singh et al., (1997), shows that risk assessment code (RAC) obtained in both wet and dry seasons for all the sampling points revealed that all the metals analyzed for the effluent sediment samples falls to the categories of high risk and very high risk. The RAC value obtained for $\mathrm{Ni}, \mathrm{Pb}$ and $\mathrm{Cd}$ were significantly high which is a concern for the environment and human health.

Table 2: Calculated Risk Assessment Code and Mobility Factor (mf \%) of the sediment samples

\begin{tabular}{llllll|lllll}
\hline \multicolumn{5}{c}{ Wet Season } & \multicolumn{1}{c|}{ Dry Season } & \multicolumn{2}{c}{} \\
Metal & $\mathrm{Mn}$ & $\mathrm{Ni}$ & $\mathrm{Co}$ & $\mathrm{Cd}$ & $\mathrm{Pb}$ & $\mathrm{Mn}$ & $\mathrm{Ni}$ & $\mathrm{Co}$ & $\mathrm{Cd}$ & $\mathrm{Pb}$ \\
\hline PT1 & 51.52 & 37.78 & 30.28 & 44.15 & 35.36 & 37.36 & 43.08 & 39.72 & 42.62 & 42.30 \\
PT2 & 46.72 & 32.24 & 30.99 & 39.16 & 43.23 & 40.76 & 43.57 & 42.18 & 39.88 & 50.24 \\
PT3 & 43.10 & 38.43 & 30.61 & 41.98 & 43.32 & 40.26 & 41.56 & 47.57 & 38.95 & 47.62 \\
PT4 & 42.65 & 48.06 & 39.56 & 39.40 & 42.12 & 37.99 & 44.92 & 41.64 & 36.66 & 39.88 \\
PT5 & 44.12 & 45.82 & 40.40 & 35.68 & 51.31 & 40.18 & 37.87 & 41.75 & 39.28 & 40.37 \\
MF\% & 45.42 & 40.99 & 37.78 & 33.85 & 43.70 & 39.41 & 41.52 & 39.62 & 42.24 & 43.92 \\
\hline
\end{tabular}

The water speciation data for $\mathrm{Mn}, \mathrm{Ni}$, $\mathrm{Cd}, \mathrm{Co}$ and $\mathrm{Pb}$ in wet and dry season as presented in Fig. 4 and Fig. 5 respectively. Mn was found predominantly in the organic fraction in both seasons. Adeyeye et al. (2016) also indicated the predominance of $\mathrm{Mn}$ in the organic fraction. It may likely due to the presence of the metal in the effluent being discharged and $\mathrm{Mn}$ due to anthropogenic and lithogenic origin in the environment. The concentrations of $\mathrm{Mn}$ analyzed were found above permissible limits by NSDWQ, 2007; WHO, 2007 and FEPA, 1999 for wastewater discharged in to surface water. For Ni, both wet and dry seasons, showed that $\mathrm{Ni}$ had the highest concentration in organic fraction. This finding is supported by Adeyeye et al. (2016). The concentrations of $\mathrm{Ni}$ in the effluent were above the maximum permissible limit set by (NSDWQ, WHO and FEPA). From the fig. 4 and 5, Co had higher concentration in suspended particle fractions in wet season and in dry season, Cobalt is found in greater quantities in organic fraction. The values of Co were above the maximum recommended limit set by WHO in both seasons (WHO, 2007). Speciation analysis of $\mathrm{Cd}$ in both wet and dry seasons shows that $\mathrm{Cd}$ were found in higher concentration in the suspended 
particle fraction. The concentration of $\mathrm{Cd}$ in both season were above the set limit of $0.05 \mathrm{mg} / \mathrm{L}$ by FEPA. Lead $(\mathrm{Pb})$ in wet season were found in higher concentration in free metal ion, indicating that the effluent was contaminated with $\mathrm{Pb}$ and that it may be readily available for plant uptake and found its way into human system. In dry season, $\mathrm{Pb}$ concentration was very high in organic substances. The concentration of $\mathrm{Pb}$ analyzed were found above the permissible limits by (NSDWQ, WHO and FEPA) for wastewater discharged into the surface water. Exposure to high $\mathrm{Pb}$ levels can severely damage the brain and kidneys and cause death. High levels of exposure to lead may cause miscarriage in pregnant women. In men, high level exposure can damage the organs responsible for sperm production (OSHA, 2004). 


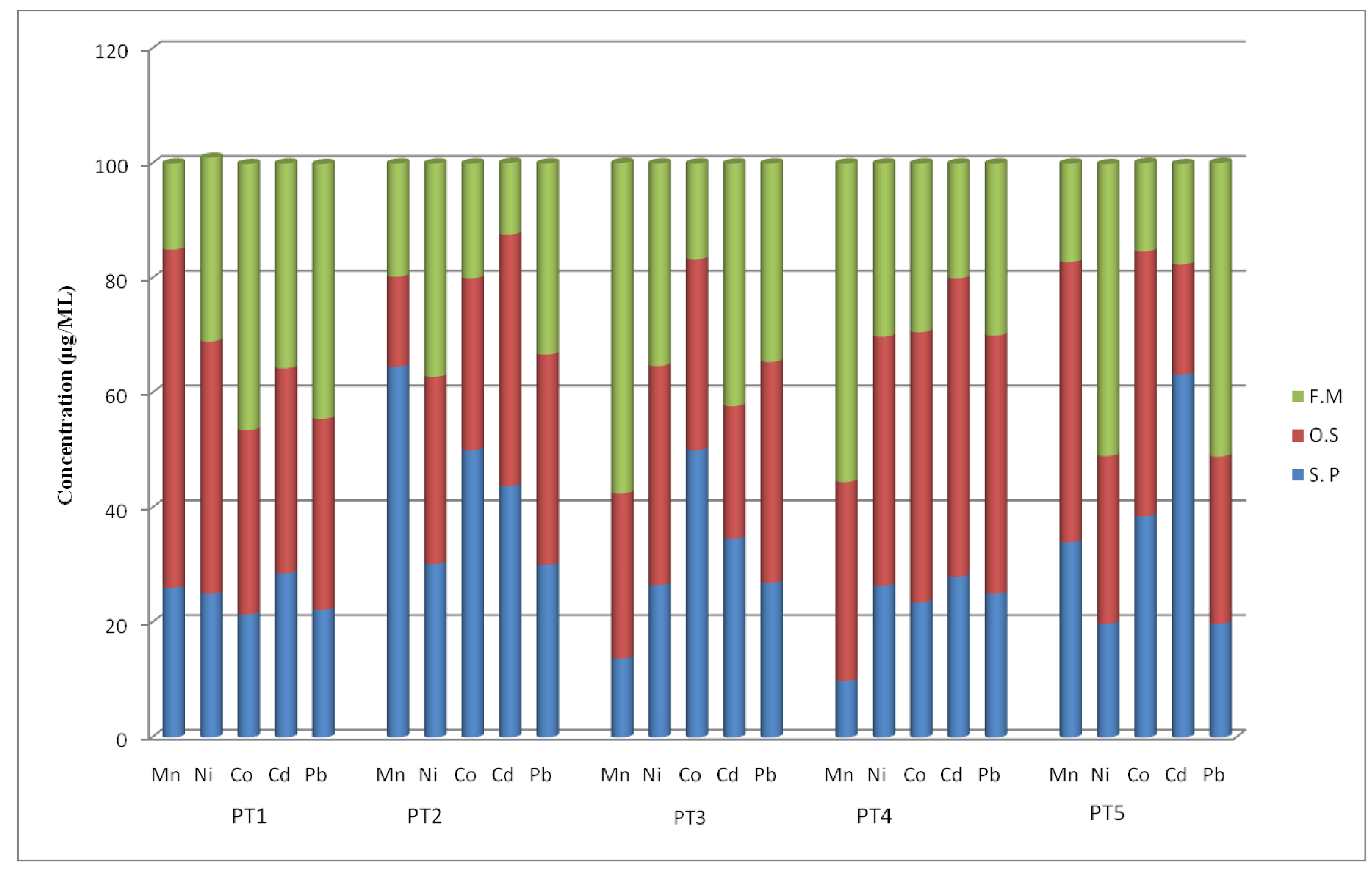

Fig. 4: Total metal concentration $(\mu \mathrm{g} / \mathrm{ml})$ in various chemical fractions in the effluent samples in wet season $\mathrm{S} . \mathrm{P}=$ Suspended Particle; O.S = Organic Substance; F.M = Free Metal ion 


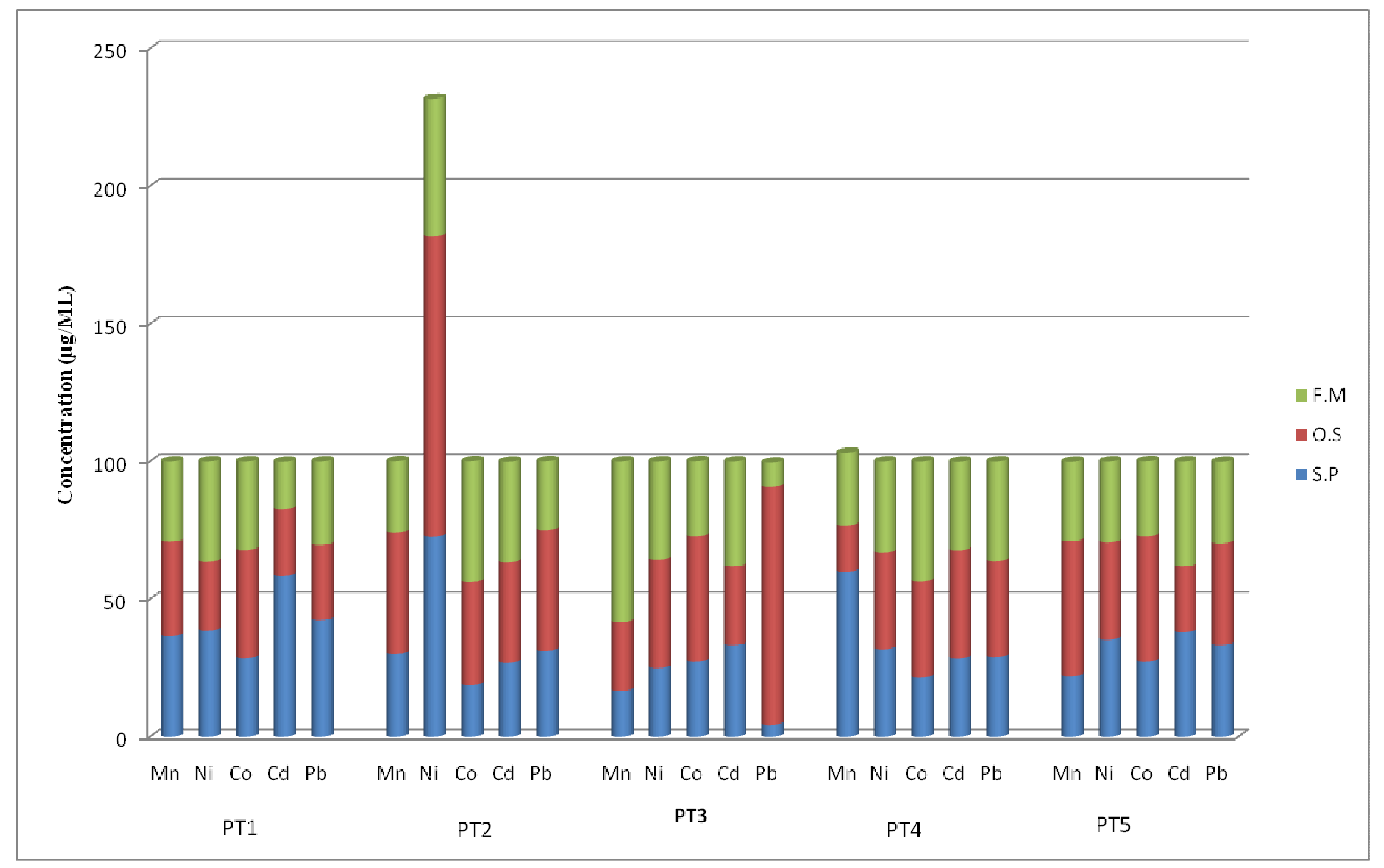

Fig. 5: Total metal concentration $(\mu \mathrm{g} / \mathrm{ml})$ in various chemical fractions in the effluent samples in dry season $\mathrm{S} . \mathrm{P}=$ Suspended Particle; O.S = Organic Substance; F.M = Free Metal ion 


\section{Conclusion}

Figures 2, 3, 4 and 5 presents chemical fractionation of both effluent and sediment. For the effluent sediment samples in wet season, it was polluted with $\mathrm{Mn}, \mathrm{Ni}$, and $\mathrm{Pb}$ while in dry season it was polluted with $\mathrm{Ni}, \mathrm{Co}$ and $\mathrm{Pb}(\mathrm{Ni}$ and $\mathrm{Pb}$ are elements of health concern) since significant amount of these metals were found in high concentration in the exchangeable and bounded to carbonate fractions which are the labile, bioavailable and toxic chemical fraction. The heavy metals concentrations in the sediment were below the set maximum permissible limit by WHO, 2003 standard except for $\mathrm{Cd}$ in both seasons. Exposure to high levels of cadmium can cause renal dysfunction, obstructive lung disease which has been linked to lung cancer. It can also cause skin irritation and ulceration. In Japan, the ltai-itai sickness associated with bone damage as a result of the regular consumption of rice contaminated with Cadmium was reported (Bulinski et al., 1993). The distribution of the studied metals in the various chemical fractions, results of mobility factors and risk assessment code confirmed their mobility, bioavailability and their potential to cause pollution. The effluent water samples were polluted with $\mathrm{Pb}$ in wet season. It was very obvious from results obtained that the effluent from the lubricant industry were loaded with $\mathrm{Ni}$ and $\mathrm{Pb}$ a major environmentally concern metal. $\mathrm{Ni}$ as one of the catalysts of hydrogenation and lead as one of the component of anti knock agent. The concentrations of heavy metals in the effluent water in both wet and dry seasons were found above the standard maximum permissible set by WHO, 2007. Therefore, a better method of waste management would be needed to avoid/curtail the menace of heavy metal pollution into the nearby aquatic environment.

\section{References}

Abdel-Shafy, H.I. and Abdel-Basir, S.E. (1991). Chemical Treatment of Industrial Wastewater. Environ. Manage. Health, 2: 19-23

Adeyeye, O.F., Olabanji, I.O., and Ogunfowokan A.O. (2016).

Chemical Fractionation of Heavy Metals in Surface Runoff and Associated Sediments of Ile-Ife and Oshogbo Township. International Journal of Environmental Protection, 6(1): 60-74.

Alvarez, E.A., Mochon, M.C., Sanchez, J.C. and Rodriguez, M.T. (2002). Heavy metal extractable forms in sludge from wastewater treatment plants. Chemosphere, 47: 765- 775.

Amos, O., Ababu, T.T. and Joseph, S.M. (2014). Assessment of Mobility and Bioavailability of Heavy metals in Sewage Slugde from Swaziland through Speciation Analysis. American Journal of Environmental Protection, 3(4): 198 - 208.

Antunes, W.M., Luna, A.S., Henriques, C.A. and Da Costa, A.C.A. (2003). An evaluation of copper biosorption by brown seaweed under optimized conditions. Elec. J. Biotechnol., 6(3): 174-184.

ATSDR, (2008). Agency for Toxic Substances and Disease Registry: ToxFAQs. Retrieved March 2009 from

http://www.atsdr.cdc.gov/toxfaq.ht $\mathrm{ml}$.

Bourg, A.C.M. (1988). Metal in aquatic and terrestrial systems: Sorption, 
speciation and mobilization. pp 3332. In :Salomons. W. and Forstner. U. (Eds). Chemistry and biology of solid waste. Berlin. Spinger-Verlag.

Brummer, G.W. (1986). Heavy metals species, mobility and availability in soil. Pp.169-192. In: Bernard, M., Brinckman, F.E. and Sadler, P.J. (E.ds). The Importance of chemical speciation in environment processes. DahlemKonferenzen, Berlin, Heidelberg, SpringerVerlag.

Bulinski, R., Bloniarz, J. and Libelt, B. (1993). Presence of some Trace Elements in Polish Food Products. XV. Contents of Lead, Copper, Cadmium, Nickel, Chromium, Zinc, Cobalt, Manganese, Copper and Iron in some Milk Products. Bromatologia i. ChemiaToks, 26: 23-27

Calvet, R., Bourgeois, S. and Msaky, J.J. (1989). Some experiments on extraction of heavy metals present in soil. J. Environ. Anal. Chem., 39: 31-45.

Davies, O.A., Allison, M.E. and Uyi, H.S. (2006). Bioaccumulation of heavy metals in water, sediments and periwinkle (Tympanotonus fuscatus var radula) from the Elechi Creek, Niger Delta: Afr. $J$. Biotechnol., 5: 10.

FEPA, (1999). Federal Environmental Protection Agency.US National series.

Forstner, U. and Wittman, G.T.W. (1981). Metal Pollution in the Aquatic Environment. Pp 486. Springer-verlag, Berlin Heidellerg, New York.
Hass, A. and Fine, P. (2010). Sequential selective extraction procedures for the study of heavy metals in soils, sediments, and waste materials - a critical Review. Environmental Science and Technololgy, 40: 365399.

Henson, M.C. and Chedrese, P.J. (2004). Endocrine disruption by cadmium, a common environmental toxicant with paradoxical effects on reproduction. Exp. Biol. Med., 229: 383-392.

Jenne, E.A. (1986). Controls on Mn, Fe, $\mathrm{Co}, \mathrm{Ni}, \mathrm{Cu}$ and $\mathrm{Zn}$ concentration in soils and water: The Significant role of hydrous $\mathrm{Mn}$ and $\mathrm{Fe}$ oxides. Pp.337-387. In R.F. Gould, R. F. (Ed.). Trace in organics in water. Adv. In Chem. Ser. 73.A. Chem. Soc., Washington, DC.

Juan, L.T.C., Nereida, P.S.T., Pedrofaustino, Z.D.V., Nely, R.D., Eduardo, M. and Sergio, G.S. (2010). Speciation and Sources of Toxic Metals in Sediments of Lake Chapala, Mexico. J. Mex. Chem. Soc., 54(2): 79-87.

McBride, M.B. (1995). Toxic metal accumulation from agricultural use of sludge. Are USEPA regulatuions protective? Journal of Environmetal Quality, 24: 5-8.

Molenaar. S.W. and Betrami, P. (1998). Heavy metal balances of an Italian soil as affect by sewage sludge and Bordeaux mixture applications. Journal of Environmental Quality. 27: 828-835.

Narwal, R.P. and Singh, B.R. (1998). Effect of organic materials on partitioning, extractability and plant uptake of metals inan alum shale, 
Soil Water Air Soil Pollut. 103: 405-421.

NSDWQ, (2007). Nigerian Standards for Drinking Water Quality: Standards on quality of surface and ground water. Federal Ministry / Agency in charge of Environment. Federal Ministry of Water Resources, Nigeria.

Pardo, M.T. and Guadalix, M.E. (1996). Zinc Sorption-desorption by 2 Andepts - effect of $\mathrm{pH}$ and Support Medium, European journal of soil science, vol. 47(2), pp. 257-263, June.

Qingsong H., Yue, R., Ibrahim, M., Maha, A., Waseem, H. and Fangui Z. (2013). Assessment of Trace and Heavy Metal Distribution by Four Sequential Extraction Procedures in a Contaminated Soil. Soil and Water Res., 8(2): 71-76.

OSHA, (2004). Occupational Health and Safety Administration: Safety and health topics: Heavy metals. http://www.osha.gov/SLTC/metalsh eavy/index.html

Salbu, B., Krekling, T. and Oughton, H.D. (1998). Characterization of radioactive particles in the environment. Analyst, 123: 843849.

Schaecke, W., Tannerberg, H. and Schilling, G. (2002). Behavior of heavy metal from sewage sludge in a chernozem of the dry belt in saxony- Anhalt/Germany. Journal of Plant Nutrition and Soil Science 165: 609-617.

Schmidt, J.P. (1997). Understanding Phytotoxicity thresholds for trace elements in land-applied sewagesludge. Journal of Environmental Quality, 26: 4-10.
Silveira, M.L.A., Alleoni, L.R.F. and Guilherme, L.R.G. (2003). Biosolids and heavy metals in soils. Scienta Agricola, 60: 793- 806.

Singh, B.R. (1997). Soil Pollution and Contamination in R. Lal (ed.), Methods of Assessment of Degradation, CRC Press, Boca Raton, FL. 279 - 299.

Tessier, A., Campbell, P.G.C. and Bisson, M. (1979). Sequential extraction procedure for the speciation of particulate trace metals. Analytical Chemistry, 51(7): 844-851.

Tokalioglu, S., Kartal, S. and Elçi, L. (2000). Speciation and Determination of Heavy Metals in Lake Waters by Atomic Absorption Spectrometry after Sorption on AmberliteXAD-16 Resin: Analytical Sciences, 16: 1169-117.

Ure, A.M. and Davidson, C.M. (2002): Chemical Speciation in the Environment. Blackie Academic and Professional, Chapman and Hall, London.

World Health Organization, WHO (2007). Combating Waterborne Diseases at the Household Level.Part1.ISBN9789241595223.h ttp://www.who.int/water_sanitation _health/publications/combating disease partllowres.pdf

World Health Organization (2003). Guidelines for Drinking Water Quality Recommendations, Vol. 1,2 nd ed, Geneva.

Xian, X. (1987). Chemical partitioning of cadmium, zinc, lead and copper in soils near smelters. J. Environ. Sci. Health, A6: 527 - 541. 